\title{
EL ÁNGEL DEL NOMBRE-EL NOMBRE DEL ÁNGEL. A MODO DE PRESENTAGIÓN
}

\section{Gracia López Anguita}

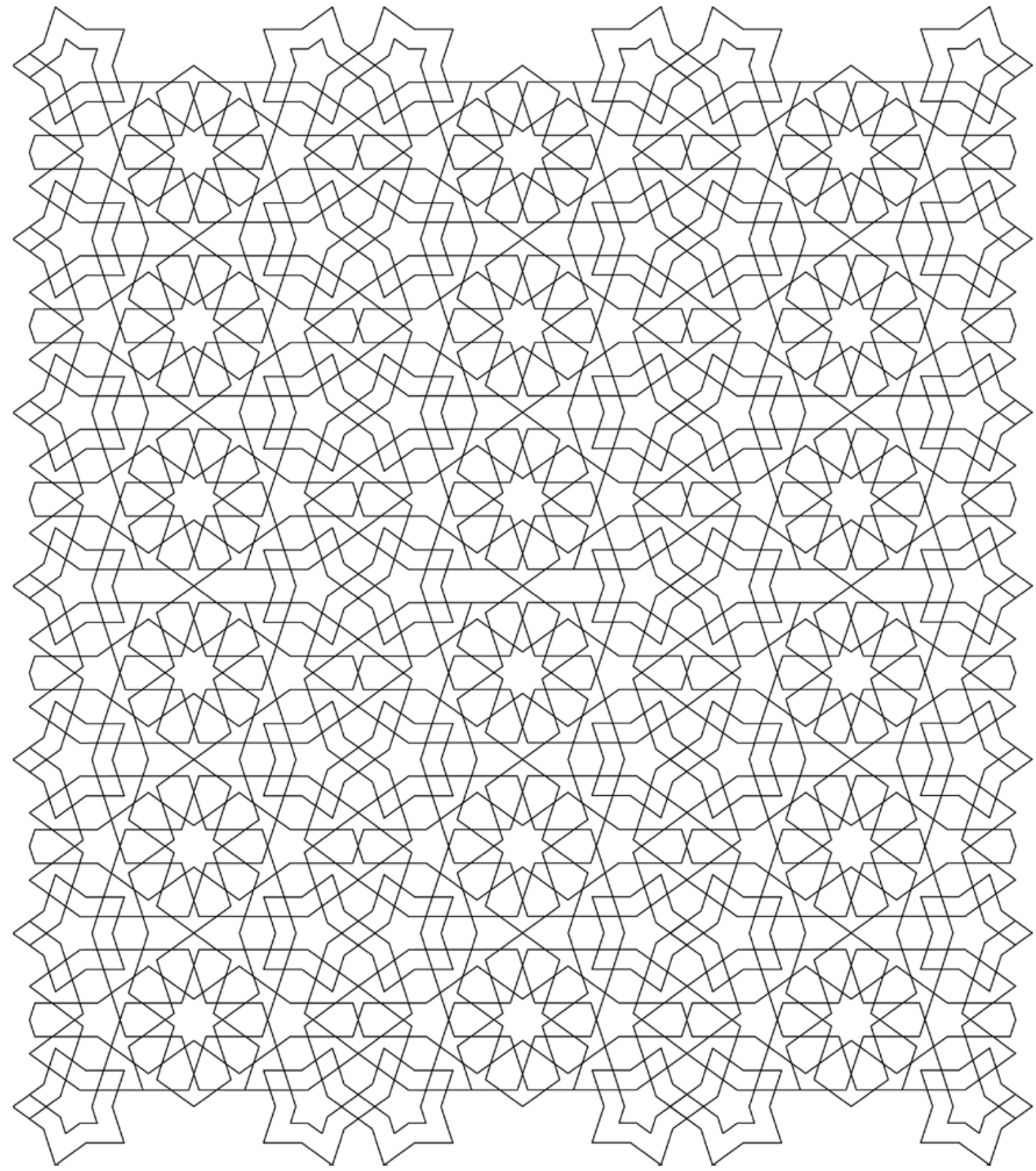


El presente número del Azufre Rojo tiene su génesis en el VII Simposio Internacional de MIAS-Latina celebrado en la Facultad de Filología de la Universidad de Sevilla en 2017 que, junto con Pablo Beneito y José Antonio Antón Pacheco, tuve el placer de organizar y que llevaba por título, precisamente, Malakút. Los ángeles en las tradiciones espirituales desde la Antigüedad. Es, de nuevo, una satisfacción y un honor, presentar este volumen en el que hemos incluido nuevas contribuciones que aportan diferentes visiones de la angelología en su sentido más amplio, esto es, el de intermediación, intercesión e interpretación.

Partiendo de una crítica muy personal al materialismo de la sociedad actual y a la superficialidad de su "oferta espiritual", Fernando Mora nos recuerda cuál es el verdadero sentido del ángel. Su artículo sintetiza los rangos y funciones de la angelología coránica, expone la paradoja de la superioridad adámica frente a la angélica y apunta un tema que será recurrente en este volumen: la relación de los ángeles con el lenguaje. En su texto se darán cita no solo los grandes místicos del islam como Ibn 'Arabī, 'Atțār o Sohravardi, sino también pensadores contemporáneos como Durand, Jung, Hillman y el imprescindible Corbin.

No podemos dejar de mencionar aquí, a propósito del islámologo francés y de la angelología, la reciente publicación de El mundo como icono. Henry Corbin y la función angélica de los seres de Tom Cheetham (Atalanta, 2019). Ya en La paradoja del monoteísmo (Losada, 2003) se otorgaba a la angelología un valor extraordinario y se planteaba audazmente que la figura del ángel podía suavizar el monoteísmo radical (e incluso el monismo) en el que las religiones abrahámicas eran susceptibles de caer; es decir, podía evitar incurrir en una idolatría metafísica. Las jerarquías de ángeles, los Nombres Divinos o, situándonos en otras tradiciones religiosas, las sefirot o la Trinidad y, en definitiva, todo aquello que suponga un principio de multiplicidad dentro de la unidad divina, cumpliría, en este sentido, la misma función además de posibilitar la teofanía.

El ensayo de Cheetham plantea un recorrido a lo largo de la trayectoria intelectual de Corbin, mostrando todas las facetas e implicaciones de su mundus imaginalis y su angelología cuyo interés, más allá del ámbito de la mera erudición, y utilidad en el pensamiento occidental moderno, el autor siempre reivindicó. El ángel es el guía del ser humano exiliado en el mundo terrenal hacia su antigua morada celeste, pero no es un agente externo, sino su propio yo interior o doble espiritual. Esta operación que consiste en un "traer de vuelta" es lo que significa literalmente la palabra ta'winl, la exégesis esotérica o anagógica propia del chiísmo y el sufismo. Es decir, para Corbin, el procedimiento de interpretación de un texto revelado y la purificación interior de la persona, es el mismo. De aquí se sigue que la interpretación que se haga de un texto puede ser diferente para cada persona y no está basada en una operación intelectual, sino en una actualización del modo de ser ya que el ejercicio interpretativo es transformante. Este camino iniciático que transcurrirá por un ámbito intersticial e imaginal, será guiado por el ángel. 
Corbin invoca la cosmología de Sohravardi para explicar el dinamismo inherente al ángel y su modo de crear imaginando. El ta'wīl išrāaq y corbiniano encuentra su objeto de contemplación e interpretación en todo lo que nos rodea: objetos, paisajes, etc. y en nuestra experiencia cotidiana, prestando especial atención a las imágenes. Las artes tendrán, por tanto, una función casi teológica: "Las artes están enraizadas de manera asombrosa en la sustancia, en el cuerpo humano (...), empiezan en la inmanencia. Pero no se detienen ahí. Lo que equivale a decir, sencillamente, que es tarea y privilegio de la estética avivar como presencia luminosa la continuidad entre temporalidad y eternidad, entre materia y espíritu." La relación de la estética y la angelología también tiene su espacio en este volumen del Azufre Rojo, como veremos más adelante.

Esta dimensión hermenéutica del ángel como transmisor e intérprete del silencio de un Dios inefable y trascendente es estudiada en el artículo presentado aquí José Antonio Antón Pacheco. Los textos gnósticos y neoplatónicos apuntalan ya esta idea que se desarrollará en la cábala y el sufismo; el pleroma angélico puede constituirse en palabras o incluso letras: "ángeles, nombres e intérpretes se encuentran en la misma secuencia ontológica." Frente a esta idea, la profusión de nombres de Dios y la exactitud del lenguaje litúrgico del mazdeísmo se sitúa en las antípodas de la concepción de Dios como un ser innombrable y silencioso, pero subraya igualmente el carácter sacro del lenguaje.

El artículo de Francisco Martínez Albarracín continúa transitando por los textos gnósticos y neoplatónicos centrándose especialmente en la obra de Pseudo-Dionisio Aeropagita y su elaborada jerarquía angélica. Albarracín trazará una analogía entre la mística cristiana y la teosofía islámica e insistirá en la importancia de la contemplación. En el texto están presentes las tierras imaginales de Hurqalya, Ğābalqā y Ğābarsā -de mención indispensable cuando de angelología se trata-, lugar donde se espiritualizan los cuerpos y se corporeizan los espíritus que, como nos recuerda el autor, no se encuentra sino dentro de uno mismo.

La idea de la ordenación de los ángeles en rangos condicionados por la cercanía a Dios y/o la función que cada uno cumple en la creación, aparece también en la cosmología de Ibn 'Arabī. Los ángeles, nos dice el Maestro, son las facultades y los sentidos del macrantropos que es el universo: "Los ángeles representan ciertas facultades de esta forma que constituye el universo, y que los iniciados designan, en el lenguaje que les es propio ‘macrocosmos'. Los ángeles son para el Universo lo que las facultades espirituales y sensibles son en la constitución del hombre."

1 El mundo como icono, p. 148.

2 Ibn 'Arabī, Los engarces de las sabidurías, trad. Andrés Guijarro, Madrid: Edaf, 2008, p. 21. 
Conviene desarrollar siquiera someramente algunos aspectos de esta jerarquía angélica akbarí $^{3}$. Los primeros ángeles creados -en singular muhayyam, cuyo nombre significa "arrobado" - se crearon a partir de las glorias de la faz de Dios y surgieron entre los atributos divinos de Majestad y Belleza. Su única actividad consiste en adorar a Dios en un continuo estado de extinción mística ( $($ ană $)$ e ignoran que existen otros seres en la creación aparte de ellos. Se esboza, cuando Ibn 'Arabī habla' de ellos, un aspecto interesante y creemos que poco estudiado, que es la relación especular entre las jerarquías angélicas y las jerarquías sufies. Así, explica: “Comparten [los ángeles arrobados] ese estado espiritual con los místicos llamados Solitarios $(a f r a \bar{d})$. Esta excepcional categoría de místicos es la única que está fuera de la supervisión del Polo (qutb), la cúspide de la jerarquía esotérica que rige cada época." 5 Los ángeles que gobiernan el mundo (mudabbira $)^{6}$ sugieren, asimismo, un paralelo con los sufies mudabbirūn, quienes, "a ejemplo de los profetas regresaron desde Dios a las criaturas, sin por ello abandonar a Dios"7 y ejercen una función de gobierno en los asuntos de este mundo. Aparte de esta equivalencia en cuanto a regencia celeste/terrestre, cada tipología de ángel representa el modelo de estación espiritual en la vía iniciática, puesto que el ángel -a diferencia de genios y humanos que pueden pasar de la impiedad a la creencia, la profecía, la santidad, etc.-, "posee una estación conocida" (Corán 37:164) y fija que no cambia.

De entre los ángeles arrobados dos fueron designados como Intelecto Primero o Cálamo y Alma Universal o Tabla, a partir de cuya interacción se desplegará el cosmos y todo lo que en él acontece. Cada constelación zodiacal y cada esfera celeste está regida por un ángel, proyectando su influencia sobre un aspecto concreto del mundo sublunar. Incluso el espacio entre las esferas -como sugiere Ibn 'Arabī en algún pasaje ${ }^{8}$ - está poblado por ángeles, lo que nos daría la imagen de un universo sin un lugar vacío de ángeles.

En la obra La alquimia de la felicidad, Ibn 'Arabī destaca la función magisterial de los ángeles que guardan cada esfera; en su particular ascenso escatológico (mírăğ), el iniciado irá aprehendiendo el conocimiento proporcionado por cada ángel que sale a su encuentro. Este aspecto del ángel como guía y maestro será llevado a su máxima elaboración por Sohravardi y Avicena. En este último, además, el ángel o "inteligencia celeste" opera como causa

3 Me he ocupado de este tema en López Anguita, Gracia, "Aproximación a la angelología en la mística islámica", en F. Roldán Castro, El cielo en el Islam, Universidad de Huelva-Universidad de Sevilla, 2014, pp. 207-228. Retomo algunas de esas cuestiones en el presente texto.

4 V. Uqlat al-mustarefiz, p. Nyberg (ed.), Leiden, 1919, 60.

5 López Anguita, G. “Aproximación”, p. 215.

6 Uqlat al-mustawfiz, p. 59.

7 Addas, Claude, Ibn 'Arabi o la búsqueda del azufre rojo, trad. Alfonso Carmona, Murcia, Editora Regional, p. 79.

8 Futūhāt, ed. Beirut, vol. 6, p. 217 
intermedia de la creación. Ambos filósofos tendrán una presencia significativa en el presente volumen.

El hecho de que el ámbito angelológico sea el de mediación e intercesión por excelencia, lleva de manera lógica a pensar que en la "magia religiosa" o teúrgia árabe, los ángeles tengan un papel central. Merece la pena dedicar unas líneas a un género, como es el de literatura esotérica, injustamente considerado menor o totalmente exento de especulación teórica seria. Efectivamente, si consultamos la obra de magia árabe clásica más conocida Šams al-Ma ārif al-kubrā de $\operatorname{Būnin}^{-9}$ (m. 1225 d. C.), encontramos nombres de ángeles profusamente usados en distintas invocaciones y talismanes. El origen mismo de la magia está ligado, en la tradición islámica, a los ángeles caídos Hārūt y Mārūt quienes, según el Corán ${ }^{10}$, transmitieron este tipo de conocimiento a los seres humanos. La licitud o no de la magia según la ley islámica depende de las opiniones de los diferentes exégetas, juristas o ulemas pero, por lo general, podemos decir que se prohibía en la medida en que podía provocar daño. En el amplio comentario coránico de Qurțubī a la aleya de Hārūt y Mārūt, explica -basándose en alQušayrī- que la magia debe considerarse kufr (impiedad) cuando tiene como objetivo el engaño. ${ }^{11}$

Como han señalado sus estudiosos, el Šams al-Ma ârif supone la adaptación de las ciencias ocultas a las prácticas devocionales del sufismo y lo incluyen dentro del género de magia religiosa, puesto que los talismanes e invocaciones en él recogidos tienen una base en el Corán. De hecho, la introducción de la obra es prácticamente toda ella una profesión de fe islámica y una afirmación de la licitud de lo contenido en el libro. A decir del propio autor, no es este un libro para ser divulgado, sino que está destinado solo para que unas élites preparadas puedan acceder a ese conocimiento.

Con frecuencia, los nombres de los ángeles son invocados junto a los de sus sirvientes genios; Būnī se dirigirá a ellos como "legión de espíritus terrenales" para que intercedan ante "los

9 De este autor, nacido en Bona ('Annaba, Argelia) y fallecido en El Cairo en la fecha arriba señalada, se tiene muy poca información biográfica. A él debemos la gran obra de referencia sobre magia árabe.

10 "Siguieron lo que recitaron los demonios (šayāṭ̄n) bajo el reinado de Salomón. [Salomón no fue incrédulo, pero los demonios lo fueron. Enseñaron a los hombres la magia negra y lo que, en Babilonia, se había revelado a los dos ángeles Hārūt y Mārūt en Babel.” Corán 2:102.

Esta historia, de la cual encontramos un paralelo en Génesis 6:1-4, fue ampliada por la tradición judía y cristiana en la literatura intertestamentaria y la literatura rabínica. Aunque se ha propuesto un origen hebreo o indio para el nombre de estos dos ángeles, estos parecen, no obstante, ser un eco de Ahurvetat y Ameretat (Integridad e Inmortalidad), dos de los arcángeles del Zoroastrismo citados entre los Amesha Spenta como parte de la escolta de Ahura Mazda.

11 Qušayrī, Latā î̉ al-ǐ̌ărāt, III, Beirut, Dār al-kutub al-ilmiyya, p. 356. Traducción nuestra. 
espíritus celestes". ${ }^{12}$ La estructura léxica de los nombres de los genios suele ser árabe, o bien persa (Muḍhib, Abyaḍ, Aḥmar, Burqān, Šamhūraš, etc.), mientras que el de los ángeles parece revelar un origen hebreo (Rūqiyāīl, Ŷabrāīl, Samsamā'̄̄l, Șarfiyā'îl, 'Ayniyā'īl, etc.). Es posible rastrear los antecedentes de estos nombres en la literatura rabínica como, por ejemplo, en el Evangelio apócrifo de Henoc (compuesto entre el s. V a. G. y el II d. C.), un texto que hace gala de una angelología que podríamos calificar de hipertrofiada.

El nombre propio del ángel es fundamental en este tipo de obras, no sólo porque es necesario para invocarlo sino porque el uso de las palabras y las letras parte de la consideración de que poseen un valor no sólo epistemológico, sino también ontológico, como base de los procedimientos alquímicos, astrológicos y adivinatorios ${ }^{13}$. La idea propia del sufismo de identificar a letras con ángeles ${ }^{14}$ alcanzará todas sus posibilidades en la literatura esotérica y la simiy $\bar{a}$ ' (la ciencia de las letras). De este modo, Būn̄̄ afirmará que cada verso coránico es un ángel: los versos que describen el Paraíso son ángeles benévolos, los versos que describen el Infierno son ángeles del castigo. El ángel de una aleya será su sentido esotérico. Y existirá, para cada letra, un nombre secreto de su ángel (idmarāt).

En el estudio que nos presenta Antonio de Diego, continuamos en el terreno de la teúrgia pero centrada en un ámbito tan poco estudiado como es el del sufismo africano. Partiendo del trabajo de campo -realizado principalmente en Senegal- y del estudio de fuentes escritas, su autor indaga en la interacción de genios y ángeles con los maestros sufíes. Este modo de ver la realidad incorpora prácticas ancestrales a un islam que no por ello debe ser calificado de popular puesto que continúa una tradición presente en el islam clásico. Este eclecticismo religioso que cuenta con un importante aporte del sufismo akbarí, ha dejado su huella en las narraciones hagiográficas locales, la ejecución de rituales y la elaboración de talismanes donde no sólo los ángeles, sino también esas otras figuras imaginales, los genios, tienen un papel fundamental.

Figura de la salutación y la salvación, el ángel cumple un papel decisivo en la historia sagrada. Así, el estudio de Heba Youssry, centrado en la unión amorosa como modo de contemplación divina y reflejo del amor de Dios hacia Sus criaturas, presentará a Gabriel como elemento clave, no solo para la creación de Jesús en el seno de María, sino para la asunción, por parte de ella, de su propio deseo sexual.

12 Seguimos la traducción de Coullat Cordero, Jaime, El Kitāb Šams al-ma ārif al-kubrà (al-ğuz'alawrwal) de Ahmad b. 'Al̄̄ al-Būñ̄: Sufismo y ciencias ocultas, tesis doctoral: Universidad de Salamanca, 2009. 13 V. Lory, Pierre, La science des lettres en Islam, París: Dervy, 2004.

14 V. The Meccan openings, trad. Grill, pp. 454-456. 
El alma, "lugar" intermedio entre el cuerpo y el espíritu, ámbito "barzají" por excelencia es al que, ontológicamente, pertenecen los ángeles. El " $t a$ 'wĭl es un proceso que compromete al alma entera" 15 nos dice Corbin, este proceso está impulsado por el deseo, el amor y el anhelo. El alma es, prácticamente de manera universal, identificada con lo femenino. Lo femenino tal y como lo presenta Ibn 'Arabī en obras como Kitäb al-huwa, en el que parte de una reflexión sobre el pronombre hiya (ella) planteando una suerte de diálogo de Dios consigo mismo, es el objeto del estudio que nos presenta Sandra Benato. Como expone su autora, la relación entre la esencia ( $d \bar{a} t$, femenina) y la Ipseidad (huwa, masculino) comportará un principo de triplicidad. Este tercer espacio que surge de la dialéctica huwa/hiya es un barzaj llamado por Ibn 'Arabī "Hálito del Misericordioso" o "el Real por medio del cual la Creación existe". Entre lo masculino y lo femenino -tanto a nivel humano como divino, es decir, como principios de inmanencia y trascendencia- se establece una relación dinámica y sin jerarquía. La receptividad pasiva atribuida tradicionalmente a la mujer y que puede incluso desprenderse de una lectura superficial y parcial de Ibn 'Arabī, será cuestionada en los trabajos aquí presentados tanto por Sandra Benato como por Heba Youssry.

Pocos conceptos hay en la cultura islámica tan controvertidos y manipulados, tanto en Occidente como en el propio mundo islámico, como el de ğihād. Este esfuerzo interior en su dimensión espiritual es el tema que ocupa la contribución de Armando Montoya. Será necesario un $t a \hat{\imath} w \bar{l} l$ que restituya su auténtico significado pero es que el propio ejercicio del

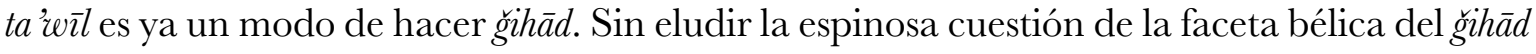
y sus manifestaciones a lo largo de la historia, el texto nos conduce a través de los últimos grandes maestros sufies como el šayh Alawi y el emir Abd al-Qadir, hasta una revisión de este concepto en clave contemplativa y no dirigido contra un enemigo exterior, sino contra la propia alma (nafs) entendida como la tendencia egoísta y pasional (en su sentido negativo) del ser humano.

La estética es el nexo común de las dos últimas contribuciones de este número. Adelantábamos más arriba la relación de la actividad imaginativa -como interpretación del mundo y acceso a lo trascendente- y las artes. Antoni Gonzalo Carbó plantea una comparación entre tres autores que proceden de disciplinas artísticas y universos - a priori- diferentes, pero en cuya obra la presencia del color rojo y las rosas está vinculada simbólicamente al ángel: el místico persa Rūzbihān Baqlī, el cineasta armenio Paradžanov y el poeta austríaco Rilke. A lo largo de un texto ricamente jalonado por las imágenes de la experiencia visionaria, se irá desplegando un mundo de referencias artísticas de la más diversa procedencia pero donde el rojo, especialmente de la sangre pero también del vino, la granada, la tierra, el alba y el crepúsculo es un heraldo del éxtasis o del sacrificio, un aviso, con resonancias alquímicas, de la epifanía del ángel. Otros significados se irán sumando a estos como los atributos de 
gloria y belleza divina simbolizados en la rosa, tan celebrada por la poesía persa, la llama -también roja- del amor, el color negro como símbolo del cuerpo y la tumba, el blanco como resurrección, etc.

El color rojo, la rosa y la imaginería de Rūzbihān Baqlī están también presentes como inspiración en la artista Ana Crespo. Como explica en su artículo, el tema del ángel es recurrente en su obra desde principios de los años 90, así como el uso del color con un valor simbólico contemplativo (tema del que se ha ocupado también desde un punto de vista teórico como investigadora). La cualidad transformadora del rojo (no olvidemos que el azufre rojo, uno de los títulos honoríficos del Šayh al-Akbar, es precisamente la sustancia capaz de transmutar el metal en oro) tiene en este texto una relevancia especial y aparece conectada al verde, color del monte $Q \bar{a} f$, final del viaje iniciático a través del mundo imaginal.

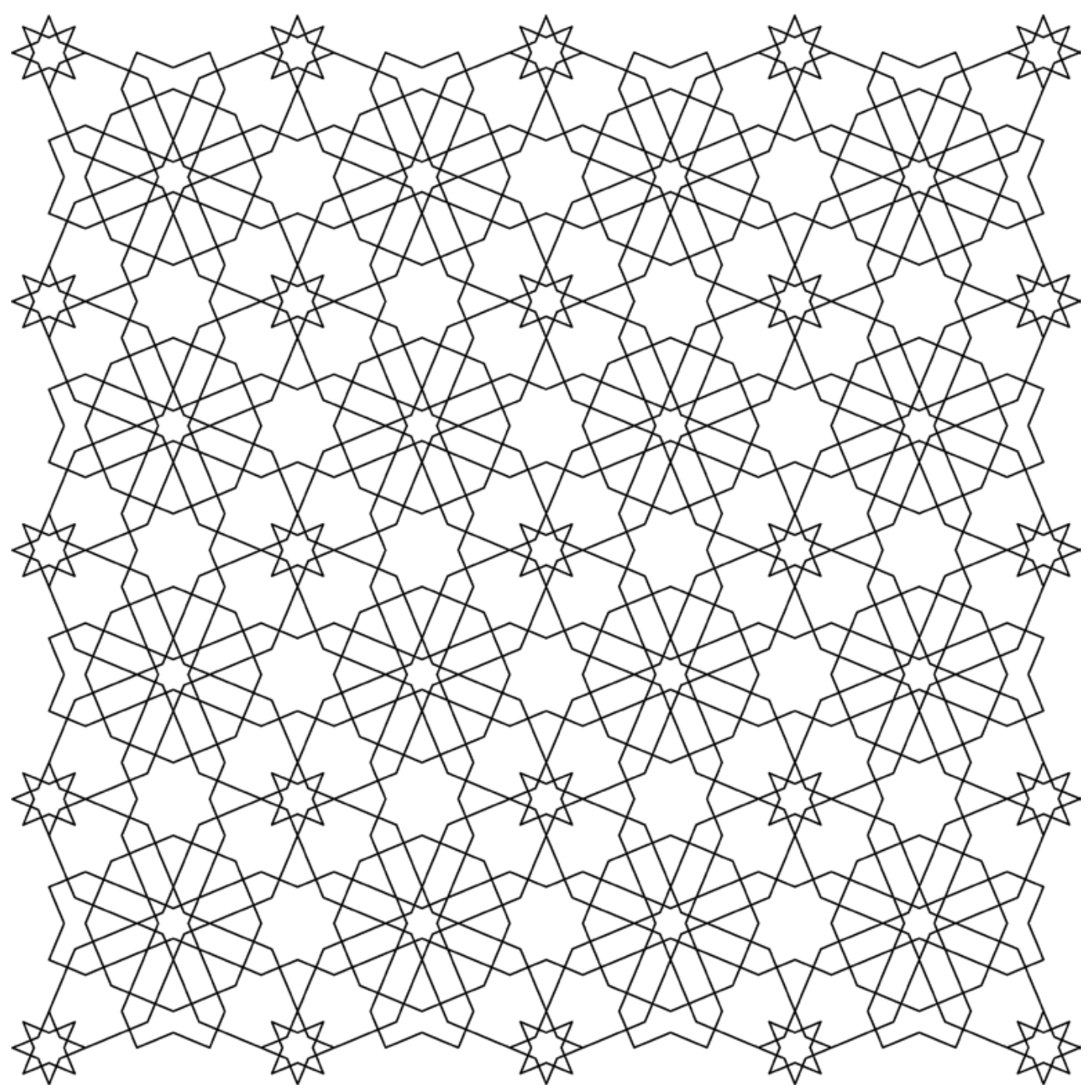

